EXTENDED REPORT

\title{
Comparison of quantitative and semiquantitative indicators of joint space narrowing in subjects with knee osteoarthritis
}

\author{
S A Mazzuca, K D Brandt, B P Katz, K A Lane, K A Buckwalter
}

See end of article for authors' affiliations

Correspondence to: Dr Steven A Mazzuca, Indiana University School of Medicine,

Rheumatology Division, 1110 W. Michigan St, Room LO 545,

Indianapolis, IN 46202-

5100, USA; smazzuca@

iupui.edu

Accepted 15 May 2005

Published Online First

26 May 2005

Ann Rheum Dis 2006;65:64-68. doi: 10.1136/ard.2005.037069

Objective: To compare quantitative estimates of change in joint space width (JSW) with semiquantitative ratings of the progression of joint space narrowing (JSN) with respect to sensitivity to change over time. Methods: 431 obese women 45 to 64 years old with unilateral radiographic knee osteoarthritis were randomised to 30 months' treatment with doxycycline $100 \mathrm{mg}$ twice daily or placebo. Quantitative estimates of change in JSW in the medial tibiofemoral compartment from fluoroscopically assisted semiflexed AP radiographs were obtained at baseline and 16 and 30 months after randomisation. Radiographic JSN was rated ( $0-3$ scale) in the same images by two readers using a standard atlas. Changes in overall severity of knee osteoarthritis were derived from gradings of conventional standing AP radiographs at baseline and 30 months, with blinding to treatment group and chronological order of examination.

Results: Follow up radiographs were obtained from 381 subjects (88\%) at 16 months and from 367 (85\%) at 30 months. The treatment groups did not differ in the frequency of significant loss of JSW by dichotomous criteria ( $\geqslant 0.5 \mathrm{~mm}, \geqslant 1.0 \mathrm{~mm}, \geqslant 20 \%$, or $\geqslant 50 \%$ of baseline JSW). Progressors and nonprogressors, as defined by each of the dichotomous outcomes, differed significantly in mean value for quantitative measurement of change in JSW at 30 months $(p \leqslant 0.001)$.

Conclusions: Quantitative and semiquantitative indicators of progression of osteoarthritis in fluoroscopically standardised radiographs of osteoarthritic knees are highly related, but the effect of doxycycline on articular cartilage thickness was more easily detected with quantitative measurements of change in JSW than with semiquantitative ratings of JSN.

$\mathrm{T}$ he advent of protocols for fluoroscopically assisted positioning of the knee in serial radiographic examinations of patients with knee osteoarthritis has been lauded as an advance that permits more precise measurements of radiographic joint space width (JSW) - the surrogate for articular cartilage thickness-and more sensitive detection of disease progression than is possible with the conventional standing anteroposterior (AP) view of the knee. ${ }^{1-3}$ However, whether precise, quantitative estimates of changes in JSW from standardised knee radiographs are superior to categorical definitions of the progression of knee osteoarthritis (that is, as a responder or non-responder, based on loss of JSW beyond the limits of measurement or on changes in semiquantitative ratings of severity of joint space narrowing (JSN)) has yet to be demonstrated.

We have recently conducted a randomised placebo controlled trial of doxycycline in subjects with unilateral knee osteoarthritis. The results of this trial, presented in detail elsewhere, ${ }^{4}$ indicate that treatment with doxycycline slowed the rate of loss of JSW over 30 months by $33 \%$ in the knee with established osteoarthritis at baseline, compared with placebo. Indeed, the precision of quantitative measurements of JSW obtained from fluoroscopically standardised knee radiographs in this study permitted the detection of a significant effect of doxycycline on the rate of loss of JSW in the index knee within only 16 months. However, doxycycline did not affect the rate of JSN in the contralateral knee. ${ }^{4}$ Herein, we compare quantitative measurements of changes in JSW with dichotomous definitions of the progression of JSN in the index knee, based on responder criteria and semiquantitative ratings of the severity of JSN, with respect to their ability to detect a difference between treatment groups in the progression of knee osteoarthritis.

\section{METHODS}

The procedures, benefits, risks, and associated safeguards in this trial were approved by the institutional review boards affiliated to the six participating clinical research centres: Indiana University - Purdue University at Indianapolis, Northwestern University, University of Alabama at Birmingham, Arthritis Research Center Foundation (Wichita KS), University of Arizona, and University of Pittsburgh.

\section{Clinical trial overview}

Subjects were 431 obese women aged 45 to 64 years with unilateral radiographic knee osteoarthritis, diagnosed on the basis of the American College of Rheumatology criteria. ${ }^{5}$ The eligibility criteria required the presence of Kellgren and Lawrence (K\&L) grade 2 or 3 changes in one knee (the index knee) and grade 0 or 1 changes in the contralateral knee $^{6}$ in a conventional weight bearing anteroposterior (AP) view of both knees in extension. All subjects were in the upper tertile of the age and race appropriate norms for body mass index (BMI) in women. ${ }^{7}$ We randomised 218 subjects to treatment with doxycycline (100 mg twice daily) for 30 months, and 213 to the placebo group. Each subject underwent a series of radiographic examinations at baseline and 16 months and 30 months later, which included a fluoroscopically standardised semiflexed anteroposterior (AP) view of each knee. ${ }^{8}$ The standing AP radiograph was repeated at 30 months to

Abbreviations: DMOAD, disease modifying osteoarthritis drug; ECHODIAH, evaluation of the chondromodulating effect of diacerein in osteoarthritis of the hip; JSN, joint space narrowing; JSW, joint space width; K\&L, Kellgren and Lawrence (radiographic criteria); WOMAC, Western Ontario and McMaster Arthritis Index 
Table 1 Baseline joint space width in the index knee and quantitative estimates of change in joint space width at 16 months and 30 months, by treatment group

\begin{tabular}{|c|c|c|c|c|c|}
\hline & \multicolumn{4}{|c|}{ Treatment group } & \multirow[b]{3}{*}{ p Value } \\
\hline & \multicolumn{2}{|c|}{ Placebo } & \multicolumn{2}{|c|}{ Doxycycline } & \\
\hline & $\mathbf{n}$ & Mean (SD) & $\mathbf{n}$ & Mean (SD) & \\
\hline $\begin{array}{l}\text { Baseline JSW }(\mathrm{mm}) \\
\text { Change in JSW at } 16 \text { months }(\mathrm{mm}) \\
\text { Change in JSW at } 30 \text { months }(\mathrm{mm})\end{array}$ & $\begin{array}{l}211 \\
191 \\
180\end{array}$ & $\begin{array}{r}3.61(1.19) \\
-0.24(0.54) \\
-0.45(0.70)\end{array}$ & $\begin{array}{l}218 \\
188 \\
181\end{array}$ & $\begin{array}{r}3.64(1.15) \\
-0.15(0.42) \\
-0.30(0.60)\end{array}$ & $\begin{array}{l}0.791^{*} \\
0.027 \dagger \\
0.017 \dagger\end{array}$ \\
\hline \multicolumn{6}{|c|}{$\begin{array}{l}\text { *Student's } t \text { test. } \\
\text { †Derived from a mixed (repeated measures) model with treatment group, clinical centre, baseline JSW, baseline } \\
\text { knee pain, visit, treatment group } \times \text { clinical centre interaction, and treatment group } \times \text { visit interaction as the } \\
\text { independent variables. } \\
\text { JSW, joint space width. }\end{array}$} \\
\hline
\end{tabular}

determine the progression of overall radiographic severity of osteoarthritis by K\&L criteria. ${ }^{6}$

\section{Quantitative measurement of JSW}

The primary outcome measure of the trial was change in JSW in the medial tibiofemoral compartment. Minimum JSW in the medial compartment was measured manually according to the method of Lequesne, ${ }^{9}$ using the points of a screw adjustable compass and a graduated loupe. Measurements were obtained from serially ordered radiographs by a reader (SAM) who was blinded to the treatment group assignment of the subject. Measurements of JSW were adjusted for radiographic magnification, based on the diameter of the projection of a $6.35 \mathrm{~mm}$ steel ball, which was fixed to the skin over the head of the fibula during the examination. The intrareader and inter-reader reproducibility of measurement of JSW, based on a random sample of 30 radiographs, was excellent (intraclass correlation coefficients $=0.985$ and 0.956 , respectively).$^{10}$

\section{Semiquantitative ratings of osteoarthritis severity}

The overall radiographic severity of knee osteoarthritis (K\&L criteria) and the severity of JSN were rated independently by two readers (SAM and KDB) who were blinded to treatment group and to the sequence of the films. K\&L grades were determined in the standing AP radiographs obtained at the screening visit and at 30 months. Medial compartment JSN in the semiflexed AP views was rated on a 0 to 3 scale, based on exemplars in a standard pictorial atlas. ${ }^{11}$ Differences between the two readers were discussed until consensus was achieved; if consensus could not be reached, a musculoskeletal radiologist $(\mathrm{KAB})$ was consulted and agreement was reached among the three examiners. After the radiographs had been read with the chronological sequence of the images masked, the films were unmasked with respect to sequence and the examiners then recorded their gestalt judgment with respect to the progression of JSN between the baseline and
16 month examination, the 16 and 30 month examination, and the baseline and 30 month examination. The reproducibility of semiquantitative ratings of overall osteoarthritis severity (K\&L grade) and severity of JSN was very high $(\kappa=0.86$ and 0.85 , respectively).

\section{Statistical analysis}

Because the analysis of primary outcomes in this trial showed a significant effect on change in JSW only in the index knee, comparisons of treatment groups with respect to alternative, dichotomous definitions of osteoarthritis progression in the present study were restricted to that knee. The original comparison of treatment groups with respect to quantitative measurements of change in JSW over 16 and 30 months was carried out with a mixed effects linear (that is, repeated measures) model, with the critical value for statistical significance set at 0.05 . The model included a random subject effect and fixed effects for treatment group, clinical centre, visit (that is, a class variable with two levels, 16 or 30 months), the clinical centre $\times$ treatment group and visit $x$ treatment group interactions, and baseline JSW and pain (WOMAC pain scale ${ }^{12}$ ) as covariates. Treatment groups were also compared at 16 months and 30 months with respect to the frequency with which the index knee showed a loss of JSW of $\geqslant 0.50 \mathrm{~mm}$. This criterion was based on our previous field test of the semiflexed AP radiograph, ${ }^{13}$ in which we found that the standard error of measurement of JSW in repeated semiflexed AP radiographs meeting quality control criteria was $0.25 \mathrm{~mm}$ (that is, 95\% confidence inter$\mathrm{val}= \pm 0.50 \mathrm{~mm})$. These comparisons were carried out using logistic regression analyses with probability (p) values for odds ratios adjusted for baseline JSW and pain.

Logistic regression models were also used to compare treatment groups with respect to three alternative dichotomous definitions of progression of JSN, based on consensus ratings: first, subjects were designated as progressors at 16 months and 30 months if the atlas based rating of severity of

Table 2 Frequency of progression of joint space narrowing in the index knee by treatment group, based on alternative dichotomous definitions of loss of joint space width relative to baseline

\begin{tabular}{|c|c|c|c|c|c|c|}
\hline \multirow{2}{*}{$\begin{array}{l}\text { Radiological } \\
\text { examination }\end{array}$} & \multirow[b]{2}{*}{ Treatment group } & \multirow[b]{2}{*}{ No of knees } & \multicolumn{4}{|c|}{ No $(\%)$ of knees with loss of JSW } \\
\hline & & & $\geqslant 0.5 \mathrm{~mm}$ & $\geqslant 1.0 \mathrm{~mm}$ & $\geqslant 20 \%$ & $\geqslant 50 \%$ \\
\hline Month 16 & $\begin{array}{l}\text { Doxycycline } \\
\text { Placebo } \\
\text { Adjusted } p \text { value }\end{array}$ & $\begin{array}{l}188 \\
191\end{array}$ & $\begin{array}{l}29(15) \\
41(22) \\
0.173\end{array}$ & $\begin{array}{l}7(4) \\
14(7) \\
0.117\end{array}$ & $\begin{array}{l}20(11) \\
26(14) \\
0.777\end{array}$ & $\begin{array}{l}5(3) \\
10(5) \\
0.292\end{array}$ \\
\hline Month 30 & $\begin{array}{l}\text { Doxycycline } \\
\text { Placebo } \\
\text { Adjusted } p \text { value }\end{array}$ & $\begin{array}{l}181 \\
180\end{array}$ & $\begin{array}{l}47(26) \\
57(31) \\
0.247\end{array}$ & $\begin{array}{l}17(9) \\
23(13) \\
0.735\end{array}$ & $\begin{array}{l}37(20) \\
41(23) \\
0.610\end{array}$ & $\begin{array}{l}13(7) \\
18(10) \\
0.714\end{array}$ \\
\hline
\end{tabular}

${ }^{*} p$ values come from logistic regression analyses and are adjusted for baseline JSW and pain.

JSW, joint space width. 
Table 330 Month progression of Kellgren and Lawrence grade and joint space narrowing: consensus of two readers who were blinded to treatment group

\begin{tabular}{|c|c|c|c|c|c|}
\hline \multirow[b]{3}{*}{ Indicator of progression } & \multicolumn{4}{|c|}{ Treatment group } & \multirow[b]{3}{*}{ p Value§ } \\
\hline & \multicolumn{2}{|c|}{ Doxycycline } & \multicolumn{2}{|c|}{ Placebo } & \\
\hline & $\mathbf{N}$ & n $(\%)$ & $\mathbf{N}$ & n $(\%)$ & \\
\hline Blind rating of medial JSN at 16 months* & 177 & $29(16)$ & 179 & $32(18)$ & 0.760 \\
\hline Blind rating of medial JSN at 30 months* & 171 & $30(18)$ & 170 & $38(22)$ & 0.285 \\
\hline Gestalt judgment of medial JSN from 0-16 months $†$ & 187 & $30(16)$ & 191 & $47(25)$ & 0.046 \\
\hline Gestalt judgment of medial JSN from 0-30 months $†$ & 181 & $50(28)$ & 180 & $60(33)$ & 0.249 \\
\hline Overall radiographic severity (K\&L grade) $\ddagger$ & 162 & $48(30)$ & 174 & $39(22)$ & 0. 188 \\
\hline \multicolumn{6}{|c|}{$\begin{array}{l}\text { *Increase by } \geqslant 1 \text { grade of severity of joint space narrowing (JSN), relative to baseline, based on exemplars from } \\
\text { standardised pictorial atlas." Knees with grade } 3 \mathrm{JSN} \text { at baseline were omitted from analysis. Radiographs were } \\
\text { rated in random sequence. } \\
+ \text { Consensus judgment of progression in serially ordered radiographs. } \\
\ddagger \text { An increase of } \geqslant 1 \text { in K\&L grade relative to baseline. Radiographs were rated in random sequence. } \\
\S A d j u s t e d \text { for clinical centre and, where appropriate, for the baseline value for the rating or grade. } \\
K \& L \text {, Kellgren and Lawrence. }\end{array}$} \\
\hline
\end{tabular}

JSN in randomly ordered pairs of semiflexed AP views increased over time by $\geqslant 1$ grade relative to baseline (knees with grade 3 medial JSN at baseline were omitted from the analysis); second, progression of JSN was based on a gestalt rating of JSN at 16 months and 30 months in serially ordered semiflexed AP radiographs; third, progression was based on the overall ratings of osteoarthritis severity (K\&L grade) in the standing AP radiograph: progressors were defined as subjects whose index knee showed an increase of $\geqslant 1$ in $K \& L$ grade. We adjusted the $\mathrm{p}$ values for knee pain and the baseline rating of severity of JSN or K\&L grade as appropriate.

To ascertain the level of agreement between semiquantitative and quantitative measures of JSN, we compared subjects who showed progression of JSN, based on dichotomous definitions, with non-progressors with respect to the mean of quantitative measurements of change in JSW. Comparisons were made using Student's $t$ test.

\section{RESULTS}

In all, 307 of the 431 randomised subjects (71\%) completed the 30 month trial per protocol (149 still taking doxycycline, 158 still taking placebo). Of the 124 dropouts, 60 returned for a semiflexed knee radiograph at 30 months, resulting in an overall rate of loss to follow up of only $14.8 \%$.

\section{Continuous change in JSW}

The treatment groups were equivalent at baseline with respect to mean JSW in the index knee (table 1 ). In the placebo group, the mean (SD) of change in JSW in the medial tibiofemoral compartment at 16 months was -0.24 (0.54) $\mathrm{mm}$; in the doxycycline group, the mean change in JSW at 16 months was $37.5 \%$ smaller in magnitude than in the placebo group $(-0.15(0.42) \mathrm{mm})$. At the 30 month examination, the underlying rate of loss of JSW was 33\% slower in the doxycycline group than in the placebo group (mean change $=-0.30 v-0.45 \mathrm{~mm}$ ). After adjustment for baseline JSW and knee pain, time, and clinical centre, the difference between treatment groups was significant at both the 16 month and the 30 month examinations $(p=0.027$ and 0.017 , respectively).

\section{Dichotomous change in JSW}

An analysis of the effects of doxycycline on change in medial JSW by dichotomous definitions of progression of JSN, based on continuous JSW measurements, is shown in table 2. Twenty nine subjects in the doxycycline group (15\%) and 41 in the placebo group (22\%) showed loss of JSW in the index knee at 16 months that was greater than the limits of the $95 \%$ confidence interval (CI) for measurement of baseline JSW (that is, $\geqslant 0.5 \mathrm{~mm}$ ). The difference between treatment groups with respect to the frequency of progression of JSN by this definition was not significant $(\mathrm{p}=0.173$ after adjustment for baseline JSW and knee pain). By a stricter criterion (JSN $\geqslant 1.0 \mathrm{~mm}$ ), the frequency of progression of JSN at 16 months in the doxycycline and placebo groups decreased by approximately two thirds $(4 \%$ and $7 \%$, respectively) in comparison with the more permissive definition, but the significance of the difference between treatment groups improved only slightly $(p=0.117)$. When progression of JSN at 16 months was defined by the percentage loss (for example, $\geqslant 20 \%$, $\geqslant 50 \%$ ) of baseline JSW, the differences in frequency between treatment groups did not approach significance (table 2).

An additional 14 months of observation did not improve the ability of dichotomous indicators of progression of JSN to reflect the significant effect of doxycycline. While table 2 shows that all such comparisons between treatment groups

Table 4 Change in joint space width at 30 months in the index knee in relation to dichotomous definitions of progression based upon consensus ratings of disease severity

\begin{tabular}{|c|c|c|c|c|c|}
\hline \multirow[b]{2}{*}{ Criteria for grading progression } & \multicolumn{2}{|c|}{$\begin{array}{l}\text { Knees showing progression of osteoarthritis } \\
\text { by dichotomous criteria }\end{array}$} & \multicolumn{2}{|c|}{$\begin{array}{l}\text { Knees not showing progression of } \\
\text { osteoarthritis by dichotomous criteria }\end{array}$} & \multirow[b]{2}{*}{ p Value } \\
\hline & $\mathbf{n}$ & $\begin{array}{l}\text { Change in JSW } \\
(\mathrm{mm} \text {, mean (SD)) }\end{array}$ & $\mathbf{n}$ & $\begin{array}{l}\text { Change in JSW } \\
(\mathrm{mm} \text {, mean (SD)) }\end{array}$ & \\
\hline $\begin{array}{l}\text { K\&L grade } \\
\text { Medial JSN, severity rating* } \\
\text { Gestalt judgment of medial JSN† }\end{array}$ & $\begin{array}{r}86 \\
68 \\
110\end{array}$ & $\begin{array}{l}-0.64(0.95) \\
-1.05(0.92) \\
-0.76(0.94)\end{array}$ & $\begin{array}{l}247 \\
272 \\
250\end{array}$ & $\begin{array}{l}-0.28(0.48) \\
-0.18(0.42) \\
-0.21(0.38)\end{array}$ & $\begin{aligned} & 0.001 \\
&< 0.001 \\
&<0.001\end{aligned}$ \\
\hline
\end{tabular}

*Based on atlas grading of films that were blinded with respect to chronological order.

†Based on the grading of films after unblinding with respect to chronological order.

JSN, joint space narrowing; JSW, joint space width; K\&L, Kellgren and Lawrence. 
with respect to the frequency of progression of JSN at 30 months favoured the doxycycline group, none approached statistical significance.

\section{Semiquantitative grading of JSN}

The effect of doxycycline, as reflected in dichotomous definitions of progression of medial JSN based on semiquantitative consensus ratings, is shown in table 3. In these atlas based ratings, which were made by readers who were blinded to the chronological order of the radiographs, the frequency of medial JSN in the two treatment groups was similar at 16 months (16-18\%) and at 30 months (18-22\%).

In comparison with the blinded, atlas based gradings of medial JSN, in which a full one point increase in a semiquantitative scale was required to define progression, gestalt judgments of progression of JSN in serially ordered radiographs detected more subtle changes and yielded much higher rates of progression (table 3 ). These judgments indicated a $35 \%$ lower frequency of progression of JSN at 16 months in the doxycycline group than in the placebo group ( $16 \% \vee 25 \%, \mathrm{p}<0.05)$. However, by 30 months, this difference was no longer significant.

\section{Progression of K\&L grade}

Based upon $K \& L$ criteria, ${ }^{6}$ the frequency of progression of overall radiographic severity of osteoarthritis at 30 months was $30 \%$ in the doxycycline group and $22 \%$ in the placebo group $(p=0.188)$ (table 3$)$. In both groups, approximately $30 \%$ of subjects with a K\&L grade of 2 at baseline showed progression to grade 3 or 4 ; among subjects with a baseline K\&L grade of $3,26 \%$ in the doxycycline group and $16 \%$ in the placebo group showed progression to grade 4 .

\section{Agreement between quantitative and semiquantitative outcomes}

Table 4 contains a summary of the extent of agreement between quantitative and semiquantitative approaches to defining progression of JSN at 30 months. Among the 86 subjects in both treatment groups who showed progression of osteoarthritis in the index knee by K\&L criteria, mean (SD) change in JSW in the medial compartment was -0.64 (0.95) $\mathrm{mm}$. In contrast, mean change in JSW among subjects who did not show progression of K\&L grade was only -0.28 $(0.48) \mathrm{mm}(\mathrm{p}=0.001)$. An even greater discrepancy in the mean of quantitative estimates of JSW loss was seen between knees in which blinded, atlas based ratings of medial JSN were positive for progression and those that did not show progression by this criterion $(-1.05(0.92) \mathrm{mm} v-0.18$ $(0.42) \mathrm{mm} ; \mathrm{p}<0.001)$. Knees in which gestalt judgments indicated JSN also showed a greater degree of loss of JSW than knees in which the gestalt judgment did not suggest JSN $(-0.76(0.94) \mathrm{mm} v-0.21(0.38) \mathrm{mm} ; \mathrm{p}<0.001$, table 4$)$.

\section{DISCUSSION}

The purpose of our study was to compare quantitative estimates of change in medial JSW with semiquantitative ratings of JSN and overall osteoarthritis severity for their sensitivity to detect a difference between treatment groups with respect to the rate of progression of knee osteoarthritis. As we have reported elsewhere, doxycycline slowed the mean rate of loss of JSW in the medial compartment of the index knee by $33 \%$ at 30 months compared with placebo, and a significant difference between the doxycycline and placebo groups in the rate of loss of JSW was already apparent in the 16 month JSN data. ${ }^{4}$ However, in contrast to its clear effect on quantitative measurements of loss of JSW, doxycycline had no effect on progression of JSN as defined by dichotomous "responder" criteria, based upon longitudinal changes in medial JSW beyond the margin of measurement error. The effect of doxycycline was apparent in gestalt judgments of progression of JSN in chronologically ordered baseline and 16 month radiographs, but not in serial pairs obtained 30 months apart. Neither the frequency of changes in atlas based semiquantitative ratings of the severity of medial JSN nor the composite grade of overall osteoarthritis severity (K\&L grade) reflected the effect of doxycycline that was apparent in quantitative measurements of change in JSW.

These data differ from the results of previous trials of purported disease modifying osteoarthritis drugs (DMOADs) in knee osteoarthritis. Recent clinical trials of glucosamine $^{14} 15$ have yielded radiographic evidence of structural modification in both continuous measurements of change in JSW and in dichotomous definitions of progression of JSN (that is, a change in JSN of more than $0.50 \mathrm{~mm}$ ). Recent placebo controlled trials of risedronate ${ }^{16}$ and intra-articular hyaluronan versus diacerein ${ }^{17}$ failed to find a DMOAD effect in either continuous or dichotomous data. However, none of these studies attempted to detect drug effects in atlas based semiquantitative ratings or gestalt judgments of JSN.

The data from the present study differ also from the results of the recent ECHODIAH study (evaluation of the chondromodulating effect of diacerein in osteoarthritis of the hip), ${ }^{18}$ in which a significant difference between the active treatment group and the placebo group was seen in the frequency of three year progression of JSN by a dichotomous definition of progression (that is, a loss of JSW of $\geqslant 0.50 \mathrm{~mm}$ ), but not in continuous measurements of change. This difference between the ECHODIAH study and the present study may reflect the substantial (nearly 50\%) rate of dropout in the former and the methods used by the ECHODIAH investigators to impute missing data. Extrapolation of interim estimates of change in JSW among the dropouts to cover the full three year period of the trial resulted in some cases in the projection of loss of significant JSW over three years, based on a non-significant change in JSW measured after only one year (for example, JSN $=0.4 \mathrm{~mm}$ after year $\mathrm{l}$ projects to $1.2 \mathrm{~mm}$ after year 3 ); some projections were made on the basis of even shorter intervals. ${ }^{18}$ This procedure may have had a disproportionate effect on the frequency of progression in the placebo group, in which dropouts had more severe osteoarthritis at baseline and more rapid loss of JSW before discontinuation of study drug than completers. At the same time, the three year extrapolation of missing data may have inflated between-subject variability of change in JSW and precluded detection of a significant difference between treatment groups with respect to mean JSN. In contrast, no data from the doxycycline trial were imputed.

While published results of DMOAD trials are still rare, numerous teams of investigators have used fluoroscopically standardised knee radiography to detect risk factors for the progression of JSN, as defined by changes in semiquantitative ratings of severity of JSN. These risk factors include varus-valgus malalignment, ${ }^{19}$ a positive late phase bone scan, ${ }^{20}$ and bone marrow oedema. ${ }^{21}{ }^{22}$ Indeed, the results of the present study indicate that knees that differ on the basis of dichotomous criteria for JSN show even more significant differences in quantitative measurements of change in JSW (table 4). While analysis of dichotomous JSN data may better illuminate the formulation of eligibility criteria for inclusion in, or exclusion from, a randomised clinical trial of a purported DMOAD, evaluation of the effects of such drugs can be more powerful if based on continuous rather than dichotomous analysis of JSN.

\section{ACKNOWLEDGEMENTS}

Data for the doxycycline trial were collected at six clinical research centres: Indiana University Medical Center (John D Bradley MD and 
Steven T Hugenberg MD), the Arthritis Research Foundation (Frederick Wolfe MD), University of Pittsburgh (Susan Manzi MD, and Chester V Oddis MD), University of Alabama at Birmingham (Larry W Moreland MD and Louis W Heck MD), Northwestern University Center for Clinical Research (Thomas J Schnitzer MD and Leena Sharma MD), and University of Arizona Arthritis Center (Davis E Yocum MD).

\section{Authors' affiliations}

S A Mazzuca, B P Katz, K A Lane, Department of Medicine, Indiana University School of Medicine, Indianapolis, IN USA

K D Brandt, Department of Medicine and Department of Orthopaedic Surgery, Indiana University School of Medicine

K A Buckwalter, Department of Radiology, Indiana University School of Medicine

Supported in part by NIH grants R01 AR43348, P60 AR20582, and R01 AR44370.

\section{REFERENCES}

1 Brandt KD, Mazzuca SA, Conrozier T, Dacre JE, Peterfy CG, Provvedini D, et al. Which is the best radiologic/radiographic protocol for a clinical trial of a structure-modifying drug in patients with knee osteoarthritis? Proceedings of January 17-18, 2002 Workshop in Toussus-le-Noble, France. J Rheumatol 2002;29:1308-20.

2 Mazzuca SA, Brandt KD, Buckwalter KA, Lane KA, Katz BP. Field test of the reproducibility of the semiflexed metatarsophalangeal (MTP) view in repeated radiographic examinations of subjects with osteoarthritis of the knee. Arthritis Rheum 2002;46:109-13.

3 Vignon E, Piperno M, Hellio Le Graverand M-P, Mazzuca SA, Brandt KD, Mathieu $P$, et al. Measurement of radiographic joint space width in the tibiofemoral compartment of the osteoarthritic knee. Comparison of standing anteroposterior and Lyon schuss views. Arthritis Rheum 2003:48:378-84.

4 Brandt KD, Mazzuca SA, Katz BP, Lane KA, Buckwalter KA, Yocum DE, et al. Effects of doxycycline on progression of osteoarthritis. Arthritis Rheum 2005;52:2015-25.

5 Altman R, Asche E, Bloch D, Bole G, Borenstein D, Brandt K, et al. Development of criteria for the classification and reporting of osteoarthritis: classification of osteoarthritis of the knee. Arthritis Rheum 1986;29:1039-49.

6 Kellgren JH, Lawrence JS. Radiographic assessment of osteoarthritis. Ann Rheum Dis 1956;16:494-502.

7 National Health, Nutrition Examination Survey II. Vital and health statistics anthropometric reference data and prevalence of overweight, DHHS Publication No PHS 87-1688, October, 1987:21-2.

8 Buckland-Wright JC, Macfarlane DG, Williams SA, Ward RJ. Accuracy and precision of joint space width measurements in standard and macroradiographs of osteoarthritic knees. Ann Rheum Dis 1995;54:872-80.
9 Lequesne M. Quantitative measurements of joint space during progression of osteoarthritis: chondrometry. In:Kuettner K, Goldberg V, editors. Osteoarthritic disorders. Rosemont, IL: American Academy of Orthopedic Surgeons, 1995:427-44.

10 Mazzuca SA, Brandt KD, Buckwalter KA, Lequesne M. Piffalls in the accurate measurement of joint space narrowing in semiflexed anteroposterior radiographs of the knee. Arthritis Rheum 2004;50:2508-15.

11 Altman RD, Hochberg M, Murphy WA, Wolfe F, Lequesne M. Atlas of individual radiographic features in osteoarthritis. Osteoarthritis Cartilage 1995;3(suppl A):3-70.

12 Bellamy N, Buchanan WW, Goldsmith CH, Campbell J, Stitt LW. Validation study of WOMAC: a health status instrument for measuring clinically important patient relevant outcomes to antirheumatic drug therapy in patients with osteoarthritis of the hip or knee. J Rheumatol 1988;15:1833-40.

13 Mazzuca SA, Brandt KD, Buckland-Wright JC, Buckwalter KA, Katz BP, Lynch JA, et al. Field test of the reproducibility of automated measurements of medial tibiofemoral joint space width derived from standardized knee radiographs. J Rheumatol 1999;26:1359-65.

14 Reginster JY, Deroisy R, Rovati LC, Lee RL, Lejeune E, Bruyere O, et al. Longterm effects of glucosamine sulphate on osteoarthritis progression: a randomised, placebo-controlled clinical trial. Lancet 2001;357(9252):251-6.

15 Pavelka K, Gatterova J, Olejarova M, Machacek S, Giacovelli G, Rovati LC. Glucosamine sulfate use and delay of progression of knee osteoarthritis: a 3year, randomized, placebo-controlled, double blind study. Arch Intern Med 2002; 162:2113-23.

16 Spector TD, Conaghan P, Buckland-Wright JC, Cline GC, Beary JF, Meyer JM. Risedronate produces disease modification and symptomatic benefit in treatment of knee osteoarthritis: results from the BRISK study. Arthritis Rheum 2003;48:3650

17 Pham T, Le Henanff A, Ravaud P, Dieppe P, Paolozzi L, Dougados M. Evaluation of the symptomatic and structural efficacy of a new hyaluronic acid compound, NDR101, in comparison with diacerein and placebo in a 1 year randomised controlled study in symptomatic knee osteoarthritis. Ann Rheum Dis 2004;63:1611-17.

18 Dougados M, Nguyen M, Berdah L, Mazieres B, Vignon, Lequesne M, et al. Evaluation of structure-modifying effects of diacerein in hip osteoarthritis. ECHODIAH, a three-year placebo-controlled trial. Arthritis Rheum $2001 ; 44: 2539-47$.

19 Sharma L, Lou C, Cahue S, Dunlop DD. The mechanism of the effect of obesity in knee osteoarthritis: the mediating role of malalignment. Arthritis Rheum 2000;43:568-75

20 Mazzuca SA, Brandt KD, Schauwecker DS, Buckwalter KA, Katz BP, Meyer JM, et al. Bone scintigraphy is not a better predictor of progression of knee osteoarthritis than Kellgren and Lawrence grade. J Rheumatol 2004;31:329-32.

21 Felson DT, Chaisson CE, Hill CL, Totterman SMS, Gale E, Skinner KM, et al. The association with bone marrow lesions with pain in knee osteoarthritis. Ann Intern Med 2001;134:541-9.

22 Felson DT, McLaughlin S, Hill CL, Goggins J, LaValley MP, Gale E, et al. Bone marrow edema and its relation to progression of knee osteoarthritis. Ann Intern Med 2003;139:330-6. 